\title{
The effect of dietary fatty acid composition on the hepatic fatty acid content and plasma lipid profile in rats
}

\author{
Tomáš Komprda ${ }^{1}$, Veronika Rozíková1, Barbora Němcová ${ }^{1}, B^{1}$ ranislav Ruttkay-Nedecký \\ ${ }^{1}$ Mendel University in Brno, Department of Food Technology, Czech Republic \\ ${ }^{2}$ Department of Chemistry and Biochemistry, Czech Republic
}

Received September 3, 2014

Accepted January 14, 2015

\begin{abstract}
The objective of the present study was to evaluate in a model organism the effect of different dietary lipids on plasma concentration of total cholesterol (TC), high-density lipoprotein cholesterol (HDL-C), low-density lipoprotein cholesterol (LDL-C) and triacylglycerols (TAG). One hundred adult male rats (Wistar Albino) were divided into 10 groups with 10 animals each and fed for 7 weeks either basic feed mixture (control diet, C) or basic feed mixture with 5\% of palm oil (P), safflower oil (SF), salmon oil (S), fish oil (F), Schizochytrium microalga oil (A), and $20 \%$ of beef tallow (T; four groups), respectively. The T-groups were fed for another 7 weeks T-, SF-, F- and A-diet, respectively. At the end of both the first and the second 7-week fattening period, plasma lipid concentration and hepatic fatty acid content was determined. Both A and $\mathrm{F}$ diets fed for 7 weeks decreased $(P<0.05)$ plasma TC $\left(0.98 \mathrm{mmol} \cdot \mathrm{l}^{-1}\right)$ compared to control $\left(1.19 \mathrm{mmol} \cdot \mathrm{l}^{-1}\right)$. The highest $(P<0.05)$ plasma TC was established in rats fed for 7 weeks the SF-diet following the previous 7 -week T-treatment $\left(2.15 \mathrm{mmol} \cdot \mathrm{l}^{-1}\right)$. A-diet had the most positive (decreasing) effect on TAG concentrations (0.68-0.86 mmol. $\mathrm{l}^{-1}$ compared to 1.22 and 2.88 $\mathrm{mmol} \cdot \mathrm{l}^{-1}$ found in the $\mathrm{C}$ and T diets, respectively; $P<0.05$ ). Both plasma TC and TAG were in a negative relationship $(P<0.01)$ with the hepatic eicosapentaenoic acid and docosahexaenoic acid (DHA) contents, respectively. It was concluded that dietary Schizochytrium microalga oil (with high DHA content) may have the potential for decreasing the risk of cardiovascular diseases.
\end{abstract}

Cholesterol, triacylglycerols, eicosapentaenoic acid, docosahexaenoic acid, fish oil, Schizochytrium microalga

Dislipidaemia (high total plasma cholesterol [TC] concentration, increased low-density lipoprotein cholesterol [LDL-C], decreased high-density lipoprotein cholesterol [HDL-C], and high concentration of plasma triacylglycerols [TAG]) is a powerful risk factor for cardiovascular diseases (CVD). Dietary fatty acid composition regulates lipids and lipoprotein metabolism and may confer CVD benefit (Ooi et al. 2013).

The major advances in the understanding of effects of dietary fatty acids on lipid metabolism have focused on long-chain polyunsaturated fatty acids of the n-3 group (LCPUFAn-3), eicosapentaenoic acid (EPA), and docosahexaenoic acid (DHA). The underlying biochemical and molecular mechanisms that can explain cardioprotective effects of EPA and DHA in rodent models and humans have been recently reviewed (Komprda 2012). However, results of studies evaluating the effects of EPA/DHA on plasma TC, HDL-C and LDL-C are contradictory (Eslick et al. 2009). Moreover, further studies are required to better understand the effects of other dietary fatty acids on plasma lipid concentrations (Ooi et al. 2013).

The objective of the present study was to evaluate in a model organism the effect of various dietary lipids with different fatty acid compositions on the deposition of these fatty acids in the liver (the most important organ regarding cholesterol metabolism) and consequently on the plasma concentration of total cholesterol, its fractions, and TAG.

Address for correspondence:

Prof. MVDr. Ing. Tomáš Komprda, CSc.

Department of Food Technology

Mendel University in Brno

Phone: +420545133261

Zemědělská 1, 61300 Brno, Czech Republic 
The rationale behind the present experiment was as follows. High plasma cholesterol and TAG concentrations are significant risk factors of atherosclerosis in humans. The rat is a relevant and mostly used research animal model regarding human atherosclerosis, despite the fact that the lipid metabolism in humans is more similar to that of a hamster or a pig (Komprda 2012). However, there is no hamster breeding available in the Czech Republic that could be used for serious research purpose, and the financial resources of the grant supporting the present study did not enable performing the experiment on pigs.

As far as dietary interventions are concerned, the intention was to use lipid sources with a presumed either positive or negative effect on the risk of atherosclerosis in humans. The following oils recommended in human nutrition were used: safflower oil with a high content of PUFA n-6 linoleic acid, fish oil with a high content of LC-PUFA n-3, and Schizochytrium microalga oil with a high content of LC-PUFA n-3, especially DHA. Palm oil (a common ingredient of many foods) with a high content of saturated fatty acids was used as a negative example. Finally, a diet based on beef tallow and sweetened evaporated milk was used; this diet is not a usual human diet as such, but it is a useful approximation of common human highly atherogenic diets with a high content of energy, saturated fats, and easily available sugars.

One of the study objectives was also testing the hypothesis that PUFA-containing "healthy" diets in the long term are able to reverse the effect of an atherogenic diet. For this purpose, after feeding the above-mentioned diets for 7 weeks, the effect of safflower oil-, fish oil- and Schizochytrium oil-diet in comparison with a tallow-based diet was tested in an additional 7 -week continuation of the feeding experiment.

\section{Materials and Methods}

\section{Animals and dietary interventions}

A total of 100 adult male rats of the laboratory strain Wistar Albino (Bio Test Ltd., Konárovice, Czech Republic) at the age of 10 weeks (the mean live weight of $337.6 \pm 5.6 \mathrm{~g}$ ) were used. Rats were housed in plastic boxes (53.5 $\times 32.5 \times 30.5 \mathrm{~cm})$ of 5 animals each in a room maintained at $23 \pm 1{ }^{\circ} \mathrm{C}$, humidity $60 \%$, and $12 / 12 \mathrm{~h} \mathrm{light} /$ dark cycle (maximum intensity of $200 \mathrm{~lx}$ ). The experiment was performed in compliance with the Czech National Council Act No. 246/1992 Coll. to protect animals against cruelty, the amended Act No. 162/1993 Coll., and was approved by the "Commission to protect animals against cruelty" of the Mendel University in Brno (Experiment Project Number 2014/2).

Basic feed mixture, pelletized complete chow for mice and rats (Biokron, Blučina, Czech Republic), composed of wheat, oat, wheat sprouts, soybean meal, extruded soybean, maize, dried milk, dried whey, dried yeast, grounded limestone, monocalcium phosphate, salt, L-lysine hydrochloride, and a premix of vitamins + minerals, was fed to all animals for the first week of the experiment (acclimatization).

Consequently, the rats were randomly placed in 10 groups (10 animals per group) and the following dietary interventions were applied for 7 weeks: basic feed mixture with maize starch (starch content $70 \mathrm{~g} \cdot \mathrm{kg}^{-1}$; control diet, $\mathrm{C}$; fed to 10 animals); basic feed mixture with palm oil $\left(50 \mathrm{~g} \cdot \mathrm{kg}^{-1} ; \mathrm{P} ; 10\right.$ animals); basic feed mixture with

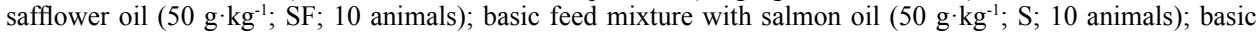
feed mixture with fish oil (commercial oleum jecoris aselli; $50 \mathrm{~g} \cdot \mathrm{kg}^{-1} ; \mathrm{F} ; 10$ animals); basic feed mixture with oil extracted from the Schizochytrium microalga (DHASCO vegetable oil from microalgae, DSM Nutritional Products North America, Parsippany, NY, USA; $50 \mathrm{~g} \cdot \mathrm{kg}^{-1} ; \mathrm{A} ; 10$ animals); and basic feed mixture with beef tallow + evaporated sweetened milk + extra vitamins/minerals premix $\left(200+400+20 \mathrm{~g} \cdot \mathrm{kg}^{-1}\right.$, respectively; T; 40 animals). The diets were prepared (at the laboratory) as follows: pelletized chow was ground, homogenized with an appropriate amount of the particular oil (in the case of the T-diet ground tallow, evaporated milk and premix), and a cake weighing $200 \mathrm{~g}$ was prepared by hand.

The animals were fed daily ad libitum and had free access to drinking water. Feed consumption was measured daily; animals were weighed at weekly intervals.

After 7 weeks of fattening the rats belonging to the C, P, SF, S, F and A groups were sacrificed (after 12-h fasting) under anaesthesia with isoflurane; blood samples were collected from the heart into the heparin-coated test tubes and centrifuged at $200 \times g$ for $10 \mathrm{~min}$ at $4{ }^{\circ} \mathrm{C}$ to obtain plasma; the liver was removed, freeze-dried and stored at $-20^{\circ} \mathrm{C}$ for subsequent fatty acid analyses.

The 40 rats (4 groups per 10 animals) consuming for 7 weeks the "atherogenic" tallow diet T were fed for another 7 weeks either the T diet, or this diet was gradually (within one week) switched to the SF, F, and A diets, respectively. The diets were prepared as mentioned above. After these extra 7 weeks of fattening, the plasma and liver samples were taken as mentioned above. 
The safflower oil (SF), fish oil (F) and alga oil (A) fed during the first seven weeks of the experiment were labeled as SF1, F1 and A1; these same diets fed following the 7-week fattening by the tallow diet were designated as SF2, F2, and A2, respectively. The time scheme of the experiment is apparent from Fig. 1.

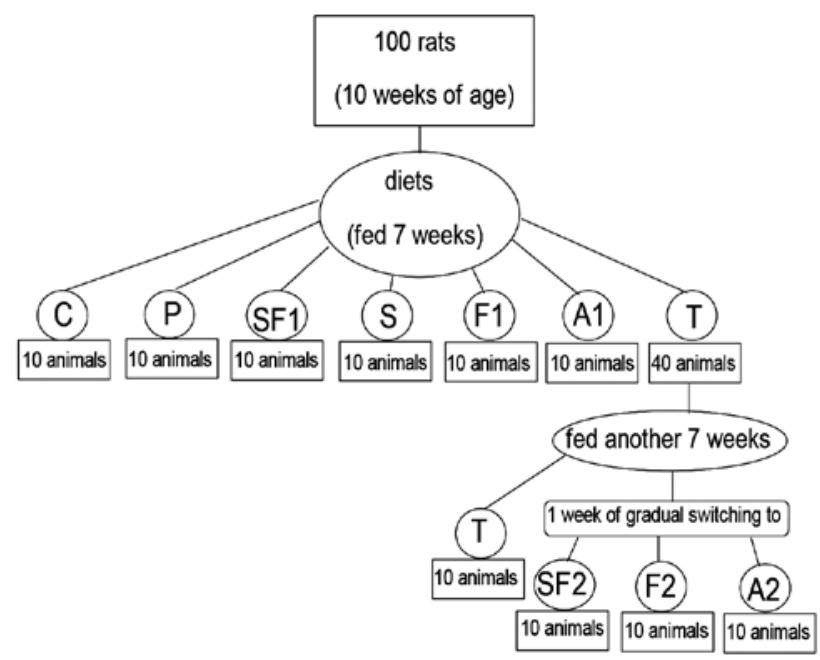

Fig. 1. The time schedule of the experiment; $\mathrm{C}$ - control diet (basic feed mixture for mice and rats with $7 \%$ [w/w] of maize starch); $\mathrm{P}$ - basic feed mixture with $5 \%$ of palm oil; SF - basic feed mixture with $5 \%$ of safflower oil; $\mathrm{S}$ - basic feed mixture with $5 \%$ of salmon oil; $\mathrm{F}$ - basic feed mixture with $5 \%$ of fish oil (commercial oleum jecoris asseli); A - basic feed mixture with 5\% of oil extracted from the Schizochytrium microalga; $\mathrm{T}$ - basic feed mixture with $20 \%$ of beef tallow $+40 \%$ of evaporated sweetened milk $+2 \%$ of extra vitamins $/$ minerals premix

Crude protein (CP) and crude fibre (CF) contents of the diets were determined using KD 310-A-1015 KjelROC Analyzer (Furulund, Sweden) and ANCOM ${ }^{220}$ Fiber Analyzer (Ancom Technology, Macedon, NY, USA), respectively. Fat content was determined gravimetrically as a hexane/2-propanol (HIP) extract (see fatty acid determination below).

Table 1. Fatty acid composition of the dietary lipid sources

\begin{tabular}{|c|c|c|c|c|c|c|}
\hline \multirow{2}{*}{ Fatty acid } & \multicolumn{6}{|c|}{ Fatty acid content in the lipid ( $\%$ of the sum of fatty acids) } \\
\hline & Beef tallow & Palm oil & Safflower oil & Salmon oil & Fish oil $^{1}$ & Microalga oil $^{2}$ \\
\hline 14:0 & 2.2 & 0.8 & 1.2 & 3.6 & 5.6 & 6.4 \\
\hline $16: 0$ & 29.4 & 39.4 & 9.1 & 11.1 & 16.3 & 16.6 \\
\hline $16: 1$ & 2.5 & 2.2 & 1.4 & 7.9 & 9.1 & 2.9 \\
\hline 18:0 & 20.6 & 4.6 & 3.9 & 2.8 & 4.1 & 3.7 \\
\hline $18: 1 n-9$ & 40.2 & 44.1 & 15.0 & 41.6 & 26.1 & 17.5 \\
\hline $18: 2 n-6$ & 2.6 & 8.4 & 62.5 & 12.8 & 10.5 & 7.9 \\
\hline $20: 4 n-6$ & 0.7 & 0.2 & 1.3 & 2.6 & 1.8 & 2.7 \\
\hline $18: 3 n-3$ & 0.9 & 0.3 & 1.2 & 4.6 & 2.4 & 2.4 \\
\hline $20: 5 n-3$ & 0.1 & ND & 1.3 & 4.3 & 9.7 & 2.9 \\
\hline $22: 5 n-3$ & ND & ND & 1.1 & 2.2 & 2.2 & 2.6 \\
\hline $22: 6 n-3$ & 0.1 & ND & 2.0 & 6.5 & 12.2 & 34.4 \\
\hline
\end{tabular}

${ }^{1}$ commercial oleum jecoris aselli

${ }^{2}$ genus Schizochytrium

$\mathrm{ND}$ - not detected 
Table 2. Content of quantitatively and physiologically important fatty acids in the diets.

\begin{tabular}{lrrrrrrr}
\hline \multirow{2}{*}{ Fatty acid } & \multicolumn{7}{c}{ Content in the diet $(\%$ of the sum of fatty acids) } \\
\cline { 2 - 8 } & \multicolumn{1}{c}{$\mathrm{C}$} & \multicolumn{1}{c}{$\mathrm{T}$} & \multicolumn{1}{c}{$\mathrm{P}$} & \multicolumn{1}{c}{$\mathrm{SF}$} & $\mathrm{S}$ & $\mathrm{F}$ & $\mathrm{A}$ \\
\hline $14: 0$ & 3.5 & 4.5 & 2.4 & 0.5 & 3.2 & 4.6 & 4.4 \\
$16: 0$ & 23.1 & 27.5 & 34.6 & 10.5 & 14.6 & 18.2 & 17.5 \\
$18: 0$ & 6.0 & 27.9 & 4.8 & 2.9 & 4.0 & 3.9 & 2.8 \\
$18: 1 \mathrm{n}-9$ & 25.3 & 33.7 & 37.4 & 17.9 & 34.2 & 26.3 & 21.6 \\
$18: 2 \mathrm{n}-6$ & 38.9 & 5.6 & 19.7 & 65.7 & 25.4 & 19.9 & 19.0 \\
$18: 3 \mathrm{n}-3$ & 3.2 & 0.8 & 1.1 & 1.1 & 5.0 & 4.3 & 1.7 \\
$20: 5 \mathrm{n}-3$ & 0.0 & 0.0 & 0.0 & 0.4 & 4.7 & 8.4 & 2.0 \\
$22: 5 \mathrm{n}-3$ & 0.0 & 0.0 & 0.0 & 0.4 & 2.3 & 2.5 & 1.9 \\
$22: 6 \mathrm{n}-3$ & 0.0 & 0.0 & 0.0 & 0.6 & 6.5 & 11.9 & 29.1 \\
\hline
\end{tabular}

$\mathrm{C}$ - control diet (basic feed mixture for mice and rats with $7 \%$ [w/w] of maize starch); $\mathrm{T}$ - basic feed mixture with $20 \%$ of beef tallow $+40 \%$ of evaporated sweetened milk $+2 \%$ of extra vitamins/minerals premix; $\mathrm{P}-$ basic feed mixture with $5 \%$ of palm oil; SF - basic feed mixture with $5 \%$ of safflower oil; $\mathrm{S}$ - basic feed mixture with $5 \%$ of salmon oil; $\mathrm{F}$ - basic feed mixture with 5\% of fish oil (commercial oleum jecoris aselli); A - basic feed mixture with 5\% of oil extracted from the Schizochytrium microalga

Ash was determined gravimetrically after incinerating an aliquot at $550{ }^{\circ} \mathrm{C}$. Nitrogen-free extractives (NFE) were calculated as a remainder to $100 \%$. The P, SF, S, F, and A diets contained $228 \mathrm{~g}$ of CP, $85 \mathrm{~g}$ of fat, $48 \mathrm{~g}$ of CF and 639 $\mathrm{g}$ of NFE per $1 \mathrm{~kg}$; metabolizable energy content (calculated from nutrients content) was $15.8 \mathrm{MJ}^{-\mathrm{kg}^{-1}}$. The content of $\mathrm{CP}$, fat, CF, and NFE in the T diet was $145,208,26$, and $621 \mathrm{~g} \cdot \mathrm{kg}^{-1}, \mathrm{ME}$ content was $18.9 \mathrm{MJ}^{\mathrm{kg}} \mathrm{kg}^{-1}$. The corresponding

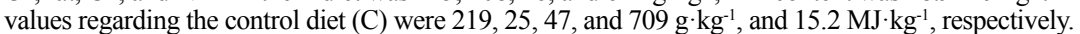

The contents of quantitatively and physiologically important fatty acids in the oils/fats used as components of the diets, and in corresponding diets are shown in Tables 1 and 2, respectively.

Fatty acid determination

The procedure according to Komprda et al. (2013) was used. An aliquot of the lyophilized sample was homogenized in a Moulinex blender (model D56, Moulinex, France) and subsequently transferred to a $150 \mathrm{ml}$ Erlenmeyer flask. Then $30 \mathrm{ml}$ of the hexane/2-propanol 3:2 (v/v) mixture (HIP 1) was added and the sample was sonicated for 15 min using a PS10000 apparatus (Notus-Powersonic, Vráble, Slovakia). The extract was filtered through a Büchner funnel and $24 \mathrm{ml}$ of an $\mathrm{Na}_{2} \mathrm{SO}_{4}$ solution was added to the filtrate. After shaking and separation of the layers in the separation funnel, the n-hexane layer was filtered through anhydrous $\mathrm{Na}_{2} \mathrm{SO}_{4}$ to a $50 \mathrm{ml}$ volumetric flask. The water layer was re-extracted with $10 \mathrm{ml}$ of HIP $2(7: 2, \mathrm{v} / \mathrm{v})$. The $\mathrm{n}$-hexane layer after re-extraction was filtered through anhydrous $\mathrm{Na}_{2} \mathrm{SO}_{4}$ and transferred to the $50 \mathrm{ml}$ volumetric flask. Combined extracts were transferred to a $100 \mathrm{ml}$ round-bottom flask and the content was evaporated on a rotary vacuum evaporator (RV 05-ST 1P-B model; IKA Labortechnik, Staufen, Germany) at $40{ }^{\circ} \mathrm{C}$. Evaporation was finished under nitrogen, and total lipids were determined gravimetrically.

An aliquot of $50 \mathrm{mg}$ of the extracted lipid was spiked with $3 \mathrm{ml}$ of the internal standard solution (15:0) and $1 \mathrm{ml}$ of butylated hydroxytoluene. Two $\mathrm{ml}$ of $0.5 \mathrm{M}$ methanolic solution of $\mathrm{CH}_{3} \mathrm{ONa}$ was added after 5 min sonication, and the methylation mixture was boiled for 5 min under reflux. Two $\mathrm{ml}$ of $14 \%$ solution of $\mathrm{BF}_{3}$ in $\mathrm{CH}_{3} \mathrm{OH}_{\text {were }}$ added through the condenser and the mixture was refluxed for another $5 \mathrm{~min}$. The sample was cooled, $2 \mathrm{ml}$ of isooctane were added, the sample was shaken and then left to stand for $1 \mathrm{~min}$. Five ml of saturated aqueous solution of $\mathrm{NaCl}$ were added and the mixture was shaken vigorously for $15 \mathrm{~s}$ while tepid. The organic layer was collected and $1 \mathrm{ml}$ was injected into the gas liquid chromatography column.

Fatty acid methyl esters (FAMEs) were separated using an HP 6890 chromatograph (Hewlett-Packard) on an Innowax capillary column $(30 \mathrm{~m} \times 0.25 \mathrm{~mm} \times 0.25 \mathrm{~mm}$; Agilent Technologies, J\&W Scientific, Santa Clara, CA, USA). Injector and detector (FID) temperatures were $260^{\circ} \mathrm{C}$ and $275^{\circ} \mathrm{C}$, respectively. The temperature program was as follows: $150{ }^{\circ} \mathrm{C} / 1 \mathrm{~min} \rightarrow$ increase by $10{ }^{\circ} \mathrm{C} / \mathrm{min}$ until $200{ }^{\circ} \mathrm{C} \rightarrow$ increase by $3{ }^{\circ} \mathrm{C} / \min$ until $260{ }^{\circ} \mathrm{C} \rightarrow$ held $3 \mathrm{~min}$. The carrier gas was $\mathrm{N}_{2}$, flow rate $1.0 \mathrm{ml} \cdot \mathrm{min}^{-1}$, pressure $145 \mathrm{kPa}$, and split ratio $60: 1$. The PUFA no. 2 (Supelco, Bellefonte, PA, USA) was used as external standards for FAMEs identification.

Plasma lipids determination

Total plasma cholesterol, LDL-cholesterol, HDL-cholesterol and triacylglycerols were determined according to Komprda et al. (2014) by the enzymatic-colorimetric method using an automated chemical analyser BS-200 (Mindray, China) and commercial kits (Greiner Diagnostic GmbH, Germany). 
Statistical evaluation

One-way analysis of the variance ratio test, including Tukey's post-hoc test, was used for evaluation of differences between the dietary interventions. Relationships between hepatic fatty acid contents and plasma markers were assessed using the Pearson correlation coefficient. The calculations were performed using the STATISTICA 12 package (StatSoft Inc., Tulsa, USA).

\section{Results}

Feed consumption and final (i.e. at the day of sacrifice) live weights of rats are shown in Table 3. When the diets were fed for the first 7 weeks, the type of oil in the diet did not influence the final live weight (non-significantly different values for the C, P, SF1, S, F1, and A1 groups; $P>0.05$; Table 3). Additional 7 weeks of fattening naturally increased $(P<0.05)$ the live weight of rats (groups T, SF2, F2, and A2); however, the live weight of A2-rats was lower $(P<0.05)$ compared to the remaining 14-weeks fed rats: it can be concluded that the Schizochytrium oil decreases live weight when consumed in the long term.

Table 3. Feed consumption and final live weights of rats.

\begin{tabular}{|c|c|c|c|c|c|c|c|c|c|c|}
\hline \multicolumn{11}{|c|}{ Diet } \\
\hline & $\mathrm{C}$ & $\mathrm{T}$ & $P$ & SF1 & SF2 & $\mathrm{S}$ & F1 & $\mathrm{F} 2$ & A1 & $\mathrm{A} 2$ \\
\hline $\begin{array}{l}\text { Feed } \\
\text { consumption } \\
\left(\mathrm{g} \cdot \text { day }^{-1}\right)\end{array}$ & $25.1^{\mathrm{a}} \pm 2.1$ & $23.1^{a} \pm 2.4$ & $24.2^{\mathrm{a}} \pm 1.9$ & $26.9^{\mathrm{ab}} \pm 1.0$ & $31.1^{\mathrm{b}} \pm 3.4$ & $23.4^{a} \pm 1.1$ & $26.6^{\mathrm{a}} \pm 1.0$ & $30.2^{\mathrm{ab}} \pm 6.4$ & $27.1^{\mathrm{a}} \pm 1.2$ & $27.0^{a} \pm 3.6$ \\
\hline $\begin{array}{l}\text { Live } \\
\text { weight }^{1}(\mathrm{~g})\end{array}$ & $430.1^{a} \pm 11.1$ & $583.1^{c} \pm 13.2$ & $444.3^{\mathrm{a}} \pm 9.2$ & $429.5^{\mathrm{a}} \pm 9.8$ & $559.8^{c} \pm 7.3$ & $429.2^{\mathrm{a}} \pm 9.1$ & $420.0^{\mathrm{a}} \pm 11.8$ & $556.5^{c} \pm 9.3$ & $429.0^{a} \pm 11.1$ & $501.8^{b} \pm 9.8$ \\
\hline
\end{tabular}

$\mathrm{C}$ - basic feed mixture for mice and rats with $7 \%(\mathrm{w} / \mathrm{w})$ of maize starch; $\mathrm{P}$ - basic feed mixture with $5 \%$ of palm oil; SF - basic feed mixture with $5 \%$ of safflower oil; $\mathrm{S}$ - basic feed mixture with $5 \%$ of salmon oil; $\mathrm{F}$ basic feed mixture with 5\% of fish oil (commercial oleum jecoris aselli); A - basic feed mixture with 5\% of oil extracted from the Schizochytrium microalga; T - basic feed mixture with $20 \%$ of beef tallow $+40 \%$ of evaporated sweetened milk $+2 \%$ of extra vitamins/minerals premix; C, P, SF1, F1, S, F1, A1 - the diets fed the first seven weeks of the experiment; T, SF2, F2, A2 - the diets fed the extra seven weeks following the seven-week fattening with the T diet;

a,b,c: means with different superscripts in rows differ significantly $(P<0.05)$; one-way analysis of the variance ratio test, including Tukey's post-hoc test; $\mathrm{n}=10$

${ }^{1}$ final live weight on the day of sacrifice

Correspondingly, the lowest $(P<0.05)$ daily weight gain $\left(1.29 \mathrm{~g} \cdot\right.$ day $\left.^{-1}\right)$ was established in rats fed the diet with Schizochytrium oil 7 weeks following the 7 -week fattening with the T-diet (diet A2). At the opposite pole was the palm oil group (P) with the live weight gain of $3.25 \mathrm{~g} \cdot$ day $^{-1}$.

As it is apparent from Fig. 2, both Schizochytrium oil and fish oil in the diet fed for 7 weeks (A1; F1) significantly decreased $(P<0.05)$ total plasma cholesterol in rats compared to the control group (C). However, the effect of both above-mentioned oils (Schizochytrium, fish) in the diets fed after previous T-fattening (A2, F2 groups) was completely contrary: total cholesterol nearly by $50 \%$ higher compared to the control rats.

The highest $(P<0.05)$ total cholesterol concentration was established in plasma of rats fed the diet with safflower oil following the T-treatment (SF2). However, it is necessary to add that this cholesterol increasing effect of safflower oil was from the greater part due to the increase in the favourable HDL fraction (SF1 and SF2 in Fig. 3). Neither fish oil nor Schizochytrium oil fed for the first 7 weeks of the experiment (F1, A1) affected plasma 


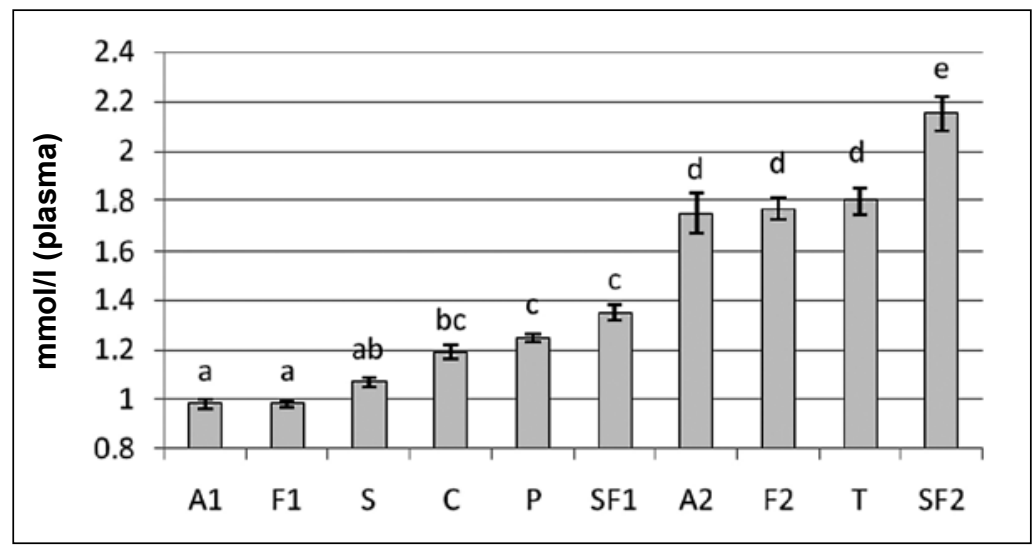

Fig. 2. Total cholesterol concentration in plasma of rats fed either the control diet (C; basic feed mixture for mice and rats with $7 \%[\mathrm{w} / \mathrm{w}]$ of maize starch) or basic feed mixture with $5 \%$ of palm oil $(\mathrm{P})$, basic feed mixture with $5 \%$ of safflower oil (SF), basic feed mixture with 5\% of salmon oil (S), basic feed mixture with $5 \%$ of fish oil (F; commercial oleum jecoris aselli), basic feed mixture with $5 \%$ of oil extracted from the Schizochytrium microalga (A) and basic feed mixture with $20 \%$ of beef tallow $+40 \%$ of evaporated sweetened milk $+2 \%$ of extra vitamins/ minerals premix (T), respectively; C, P, SF1, F1, S, A1 - diets fed for the first 7 weeks of the experiment; T, SF2, F2, A2 - diets fed for the extra 7 weeks following the seven-week fattening with the T diet; a - e: means labelled with different letters differ significantly $(P<0.05)$; one-way analysis of the variance ratio test, including Tukey's post-hoc test; $\mathrm{n}=10$

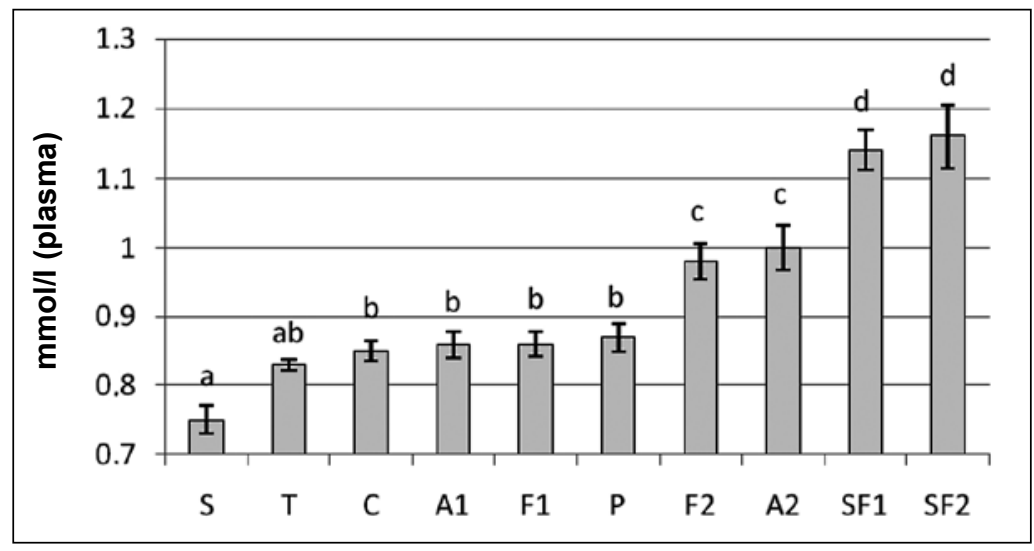

Fig. 3. High-density lipoprotein-cholesterol concentration in plasma of rats fed either the control diet (C; basic feed mixture for mice and rats with $7 \%[\mathrm{w} / \mathrm{w}]$ of maize starch) or basic feed mixture with $5 \%$ of palm oil $(\mathrm{P})$, basic feed mixture with $5 \%$ of safflower oil (SF), basic feed mixture with $5 \%$ of salmon oil (S), basic feed mixture with $5 \%$ of fish oil (F; commercial oleum jecoris aselli), basic feed mixture with $5 \%$ of oil extracted from the Schizochytrium microalga (A) and basic feed mixture with $20 \%$ of beef tallow $+40 \%$ of evaporated sweetened milk $+2 \%$ of extra vitamins/minerals premix (T), respectively; C, P, SF1, F1, S, A 1 - diets fed for the first 7 weeks of the experiment; T, SF2, F2, A2 - diets fed for the extra 7 weeks following the 7-week fattening with the T diet; a-d: means labelled with different letters differ significantly $(P<0.05)$; one-way analysis of the variance ratio test, including Tukey's post-hoc test; $\mathrm{n}=10$

HDL cholesterol compared to control (C), contrary to the effect of these oils administered after previous fattening with the "atherogenic" T-diet (F2, A2; Fig. 3).

As far as the LDL cholesterol fraction is concerned (Fig. 4), the lowering (i.e. favourable) 


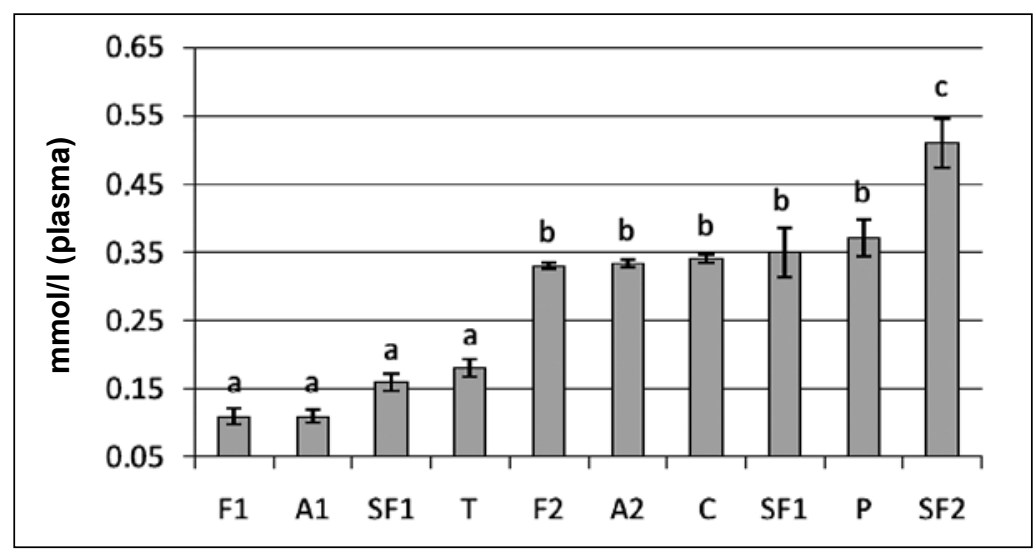

Fig. 4. Low-density lipoprotein-cholesterol concentration in plasma of rats fed either the control diet (C; basic feed mixture for mice and rats with $7 \%[\mathrm{w} / \mathrm{w}]$ of maize starch) or basic feed mixture with $5 \%$ of palm oil (P), basic feed mixture with 5\% of safflower oil (SF), basic feed mixture with 5\% of salmon oil (S), basic feed mixture with $5 \%$ of fish oil (F; commercial oleum jecoris aselli), basic feed mixture with 5\% of oil extracted from the Schizochytrium microalga (A) and basic feed mixture with $20 \%$ of beef tallow $+40 \%$ of evaporated sweetened milk $+2 \%$ of extra vitamins/minerals premix (T), respectively; C, P, SF1, F1, S, A1 - the diets fed for the first 7 weeks of the experiment; T, SF2, F2, A2 - diets fed for the extra 7 weeks following the 7-week fattening with the T diet; a-c: means labelled with different letters differ significantly $(P<0.05)$; one-way analysis of the variance ratio test, including Tukey's post-hoc test; $\mathrm{n}=10$

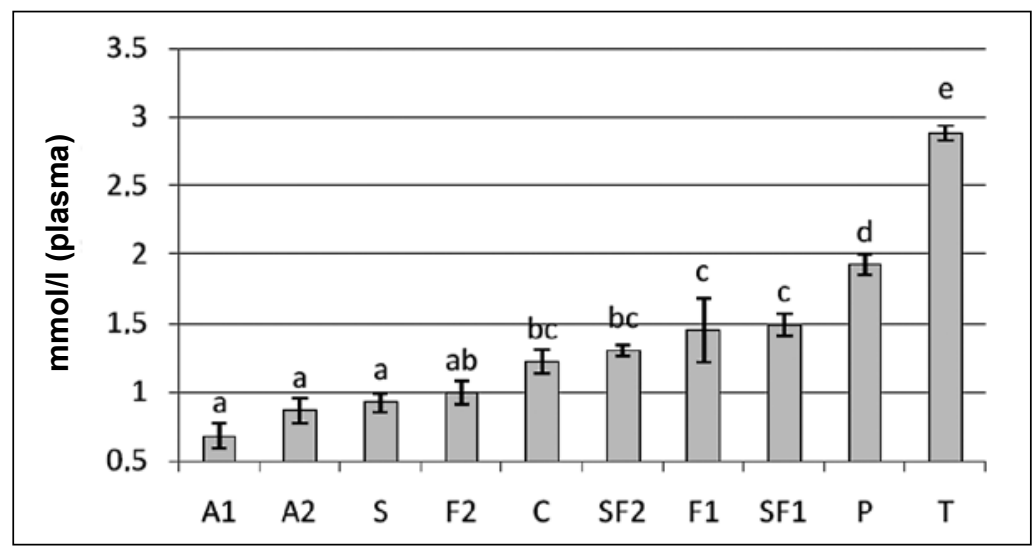

Fig. 5. Triacylglycerol concentration in plasma of rats fed either the control diet $(\mathrm{C}$; basic feed mixture for mice and rats with $7 \%$ [w/w] of maize starch) or basic feed mixture with $5 \%$ of palm oil $(\mathrm{P})$, basic feed mixture with $5 \%$ of safflower oil (SF), basic feed mixture with $5 \%$ of salmon oil (S), basic feed mixture with $5 \%$ of fish oil (F; commercial oleum jecoris aselli), basic feed mixture with $5 \%$ of oil extracted from the Schizochytrium microalga (A) and basic feed mixture with $20 \%$ of beef tallow $+40 \%$ of evaporated sweetened milk $+2 \%$ of extra vitamins/ minerals premix (T), respectively; C, P, SF1, F1, S, A1 - diets fed for the first 7 weeks of the experiment; T, SF2, F2, A2 - diets fed for the extra 7 weeks following the 7-week fattening with the T diet; a-e: means labelled with different letters differ significantly $(P<0.05)$; one-way analysis of the variance ratio test, including Tukey's posthoc test; $\mathrm{n}=10$

effect compared to control was established in fish oil, Schizochytrium oil, and safflower oil fed the first 7 weeks of the experiment (F1, A1, SF1), but surprisingly also in the tallow/ evaporated milk diet $\mathrm{T}$. 
Table 4. Fatty acid content in the liver.

\begin{tabular}{|c|c|c|c|c|c|c|c|c|c|c|}
\hline \multirow{2}{*}{ Fatty acid } & \multicolumn{10}{|c|}{ Fatty acid content (mg/100 $\mathrm{g}$ of the liver tissue; fresh weight) [mean $\pm \mathrm{SEM}]$} \\
\hline & $\mathrm{C}$ & $\mathrm{T}$ & $\mathrm{P}$ & SF1 & SF2 & $\mathrm{S}$ & $\mathrm{F} 1$ & F2 & $\mathrm{A} 1$ & $\mathrm{~A} 2$ \\
\hline$\overline{14: 0}$ & $27^{\mathrm{bc}} \pm 2$ & $46^{\mathrm{e}} \pm 3$ & $26^{\mathrm{ab}} \pm 1$ & $23^{\mathrm{ab}} \pm 3$ & $19^{a} \pm 1$ & $24^{\mathrm{ab}} \pm 1$ & $39^{\text {de }} \pm 2$ & $31^{\mathrm{bc}} \pm 1$ & $34^{\mathrm{cd}} \pm 2$ & $30^{b \mathrm{bc}} \pm 1$ \\
\hline $16: 0$ & $712^{\mathrm{ab}} \pm 13$ & $980^{\text {ef }} \pm 48$ & $802^{\text {bed }} \pm 14$ & $772^{\mathrm{bc}} \pm 32$ & $841^{\text {de }} \pm 32$ & $640^{\mathrm{a}} \pm 36$ & $1033^{f} \pm 44$ & $957^{\mathrm{ef}} \pm 18$ & $861^{\text {ded }} \pm 25$ & $926^{\text {def }} \pm 17$ \\
\hline 18:0 & $373^{a} \pm 5$ & $464^{c} \pm 13$ & $441^{\circ} \pm 12$ & $444^{b c} \pm 23$ & $450^{c} \pm 12$ & $376^{\mathrm{ab}} \pm 18$ & $499^{c} \pm 20$ & $471^{\circ} \pm 10$ & $356^{a} \pm 18$ & $433^{\mathrm{abc}} \pm 8$ \\
\hline $18: \ln -9$ & $438^{b} \pm 10$ & $1298^{e} \pm 91$ & $715^{d} \pm 18$ & $267^{a} \pm 20$ & $587^{\mathrm{cd}} \pm 37$ & $490^{b c} \pm 26$ & $500^{\mathrm{bc}} \pm 2$ & $730^{d} \pm 21$ & $399^{\mathrm{ab}} \pm 28$ & $597^{\mathrm{cd}} \pm 28$ \\
\hline $18: 2 n-6$ & $351^{a} \pm 12$ & $410^{\mathrm{ab}} \pm 17$ & $510^{b c} \pm 15$ & $1272^{\mathrm{f}} \pm 54$ & $1398^{\mathrm{f}} \pm 82$ & $573^{\text {cd }} \pm 28$ & $718^{\text {de }} \pm 31$ & $762^{\mathrm{e}} \pm 20$ & $555^{\text {bcd }} \pm 70$ & $601^{\text {de }} \pm 15$ \\
\hline $20: 4 n-6$ & $434^{\mathrm{bc}} \pm 11$ & $284^{a} \pm 7$ & $475^{c} \pm 12$ & $779^{e} \pm 35$ & $642^{\mathrm{d}} \pm 13$ & $351^{\mathrm{a}} \pm 28$ & $354^{\mathrm{ab}} \pm 14$ & $265^{a} \pm 65$ & $610^{d} \pm 41$ & $567^{\mathrm{d}} \pm 10$ \\
\hline $18: 3 n-3$ & $67^{a} \pm 1$ & $24^{\mathrm{de}} \pm 1$ & $12^{\mathrm{bc}} \pm 1$ & $10^{\mathrm{ab}} \pm 1$ & $36^{\mathrm{f}} \pm 3$ & $35^{\mathrm{f}} \pm 2$ & $29^{e} \pm 2$ & $47^{g} \pm 2$ & $17^{\mathrm{dd}} \pm 2$ & $39^{f} \pm 2$ \\
\hline $20: 5 n-3$ & $6^{\mathrm{a}} \pm 1$ & $13^{\mathrm{a}} \pm 1$ & $5^{\mathrm{a}} \pm 0$ & $3^{\mathrm{a}} \pm 1$ & $8^{a} \pm 1$ & $258^{d} \pm 8$ & $342^{e} \pm 15$ & $216^{\mathrm{c}} \pm 10$ & $78^{b} \pm 6$ & $74^{b} \pm 3$ \\
\hline $22: 5 n-3$ & $28^{\mathrm{a}} \pm 2$ & $26^{\mathrm{a}} \pm 1$ & $24^{a} \pm 1$ & $13^{a} \pm 1$ & $27^{\mathrm{a}} \pm 1$ & $128^{c} \pm 7$ & $124^{c} \pm 9$ & $138^{\circ} \pm 4$ & $46^{b} \pm 3$ & $48^{b} \pm 3$ \\
\hline $22: 6 n-3$ & $99^{\mathrm{a}} \pm 2$ & $118^{\mathrm{a}} \pm 5$ & $112^{a} \pm 4$ & $83^{a} \pm 5$ & $131^{a} \pm 5$ & $477^{b} \pm 16$ & $571^{\mathrm{c}} \pm 33$ & $436^{b} \pm 11$ & $609^{c} \pm 41$ & $597^{\mathrm{c}} \pm 31$ \\
\hline
\end{tabular}

$\mathrm{C}$ - basic feed mixture for mice and rats with $7 \%(\mathrm{w} / \mathrm{w})$ of maize starch; $\mathrm{P}$ - basic feed mixture with $5 \%$ of palm oil; SF - basic feed mixture with 5\% of safflower oil; $\mathrm{S}$ - basic feed mixture with $5 \%$ of salmon oil; $\mathrm{F}$ - basic feed mixture with $5 \%$ of fish oil (commercial oleum jecoris aselli); A - basic feed mixture with $5 \%$ of oil extracted from the Schizochytrium microalga; T - basic feed mixture with $20 \%$ of beef tallow $+40 \%$ of evaporated sweetened milk $+2 \%$ of extra vitamins/minerals premix; C, P, SF1, F1, S, A1 - diets fed for the first 7 weeks of the experiment; T, SF2, F2, A2 - diets fed for the extra 7 weeks following the 7-wk fattening with T diet; a-e: means with different superscripts in lines differ significantly $(P<0.05)$; one-way analysis of the variance ratio test, including Tukey's post-hoc test; $\mathrm{n}=10$

The most positive (i.e. decreasing) effect on the rat plasma TAG concentrations $(P<$ 0.05 ) had Schizochytrium oil (both A1 and A2 treatments; Fig. 5). As expected, palm oil, and especially the T-diet substantially increased $(P<0.05)$ TAG compared to control.

Fatty acid concentrations in the liver are presented in Table 4. Regarding saturated fatty acids, very high deposition of palmitic acid (16:0) was unexpectedly found in the liver of rats fed the F- and A-diets, respectively (higher, $P<0.05$, deposition compared to control). Very high content of linolenic acid (18:2n-6) in safflower oil manifested itself in the highest $(P<0.05)$ hepatic deposition in both SF groups.

As far as the long-chain PUFA n-3 are concerned, the highest hepatic $(P<0.05)$ EPA and DHA depositions were a consequence of feeding the diet with fish oil (F1) and Schizochytrium oil (A1, A2), respectively.

The main purpose of measuring fatty acids content in the liver (the most important organ regarding cholesterol metabolism) was to assess the relationships between hepatic fatty acids concentration and plasma cholesterol concentration. Based on the correlation analysis and considering the coefficient of correlation significant at the level of $P<0.01$ (total number of measurements $\mathrm{n}=100$ ), the total plasma cholesterol concentration was in a positive relationship with the hepatic concentrations of oleic acid (18:1n-9; $\mathrm{r}=$ $0.38)$, linoleic acid $(18: 2 n-6 ; r=0.37)$, and $\alpha$-linolenic acid $(18: 3 n-3 ; r=0.35)$, and in a negative relationship with the hepatic content of EPA and DHA $(r=-0.32$ and $r=-0.23$, respectively).

Hepatic linoleic acid and arachidonic acid (20:4n-6) contents were in a positive relationship with HDL-C $(r=0.55$ and $r=0.36$, respectively). A lowering (i.e. positive) effect on plasma LDL-C can be presumed in case of hepatic DHA $(\mathrm{r}=-0.25)$, but surprisingly also in case of saturated myristic acid $(\mathrm{r}=-0.33)$.

Plasma TAG concentration was in a positive correlation with oleic acid $(\mathrm{r}=0.49)$, and in a negative relationship with EPA, DPA $(22: 5 n-3)$ and DHA $(r=-0.33,-0.37$, and -0.51 , respectively). 


\section{Discussion}

Similarly to the present experiment (Fig. 2), fish oil in the rat diet decreased plasma TC also in most recent studies (e.g. Lu et al. 2011; Campioli et al. 2012; Komprda et al. 2014). The TC value established in the present experiment after feeding the F1 diet $\left(0.98 \mathrm{mmol}^{-1^{-1}}\right)$ is the same as found in the experiment of Takahashi (2011). However, other authors reported mostly higher values (recalculated to $\left.\mathrm{mmol}^{-1} \mathrm{l}^{-1}\right): 3.22(\mathrm{Lu}$ et al. 2011), 2.45 (Ferramosca et al. 2012), and 2.04 (Campioli et al. 2012).

Chen et al. (2011) reported a significant decrease of plasma TC in hamsters fed a diet containing Schizochytrium lipid extract compared to control, which is also in agreement with our data regarding the A1 diet (Fig. 2).

Safflower oil in the SF1 diet tended to increase $(P=0.08)$ TC compared to control (by $13 \%$ ); Poudyal et al. (2013) similarly reported a non-significant increase of TC using a diet with safflower oil.

Neither fish oil nor Schizochytrium oil in the diet was able to reverse the cholesterolincreasing effect of the "atherogenic" T-diet in the present experiment (the same TC values of the A2, F2 and T diet, Fig. 2). The linoleic acid-rich safflower oil diet SF2 even increased $(P<0.05)$ TC above the concentration established in the T-rats. This result disagrees with the data of Poudyal et al. (2013) who found no significant difference in TC between rats fed a diet with safflower oil; high carbohydrate, high fat diet with safflower oil; and a control starch diet.

It is interesting that the diet containing palm oil with a high content of saturated palmitic acid did not increase TC above the concentration established either in control rats or in rats fed the SF1 diet, rich in polyunsaturated linoleic acid (Fig. 2). According to Fattore et al. (2014), palm oil diets, compared with diets rich in stearic acid, monounsaturated fatty acids, or polyunsaturated fatty acids, showed significantly higher TC values based on the meta-analysis of human dietary intervention trials.

The significant negative correlation $(P<0.01)$ between the total plasma cholesterol concentration and hepatic EPA or DHA concentrations established in the present experiment, does not necessarily mean a causative relationship. It nevertheless confirms the hypothesis that EPA/DHA may activate a signal pathway (via the transcription factors peroxisome proliferator-activated receptor [PPAR] $\alpha$ and sterol regulatory element-binding protein [SREBP] 2) leading to a decreased expression of the gene coding for the key enzyme of cholesterol biosynthesis, 3-hydroxy-3-methyl-glutaryl Coenzyme A reductase, and consequently to decreased plasma cholesterol concentration (König et al. 2007).

Experiments evaluating the effects of dietary lipids on rat plasma HDL-C use mostly diets containing fish oil. In concordance with the inconsistent results of the present study (F1 diet did not change, F2 diet increased HDL-C compared to control; Fig. 3), Popović et al. (2011), Takahashi (2011), and Campioli et al. (2012) reported an increase, a decrease, and no change, respectively, in HDL-C in rats fed diets with fish oil compared to particular control diets.

The same inconsistency regards also LDL cholesterol: a diet with fish oil decreased this plasma marker in rats in some experiments (e.g. Popović et al. 2011), but did not change it in others (Campioli et al. 2012); compare data concerning F1 and F2 diets in the present experiment (Fig. 4).

As far as plasma TAG concentration in the present experiment is concerned, the most favourable effect (significant decrease compared to control) of the diets containing Schizochytrium microalga oil and salmon oil (Fig. 5) is consistent with the composition of these oils, namely the high content of LC-PUFA n-3. Among all tested hepatic fatty acids, only EPA, DPA, and DHA concentrations were in a significant $(P<0.01)$ negative relationship with plasma TAG concentration in the present experiment. A TAG decreasing 
effect of these LC-PUFAs n-3 can therefore be presumed. This finding can be explained by the fact that EPA and DHA reduce TAG synthesis via inhibition of diacylglycerol acyltransferase, fatty acid synthase, and acetyl CoA carboxylase enzymes; enhance fatty acid $\beta$-oxidation via a PPAR $\alpha$-mediated pathway resulting in decreased substrate availability for TAG formation; and suppress transcription of SREBP-1c gene with a consequence of inhibition of de-novo lipogenesis (Mozaffarian and Wu 2011).

The present study concerned some important factors affecting the risk of atherosclerosis in humans: TC, HDL-C, LDL-C, and TAG. The effect of diets with favourable (high PUFA content) and unfavourable (high saturated fatty acid content) composition of the lipid fraction was compared using a rat model. Moreover, the hypothesis that the effect of hypercholesterolaemic and hypertriglyceridaemic diets can be reversed by subsequent administration of PUFA-rich oils was tested.

Based on the above-mentioned objectives of the study, it can be concluded that both Schizochytrium oil and fish oil administered medium-term decreased total plasma cholesterol; these oils increased this marker after long-term administration, but due to the increase of the favourable HDL-C fraction. This is in agreement with the conclusions of a meta-analysis of Jacobson et al. (2012) based on results of the human clinical studies: a net increase in HDL-C (but also LDL-C) due to EPA/DHA intake.

Moreover, a great potential of the Schizochytrium microalga, with its high content of DHA, to decrease the risk of atherosclerosis and CVD in humans follows from the results of the present study: dietary Schizochytrium oil substantially decreased the live weight of model animals after previous consumption of an atherogenic/live weight-increasing diet, and significantly decreased plasma TAG compared to both the "neutral" control diet (on average a $\times 1.5$ decrease) and the "atherogenic" T-diet (on average nearly a $\times 4$ decrease), when administered both medium-term ( 7 weeks) and long-term (14 weeks).

On the other hand, safflower oil, containing about $63 \%$ of linoleic acid from the sum of total fatty acids, was superior to both Schizochytrium oil and fish oil in increasing the favourable cholesterol fraction (HDL-C) in the rat plasma, and can therefore be also recommended for human nutrition.

\section{Acknowledgements}

The experiment was supported by the Internal Grant Agency of the Mendel University in Brno (project No. TP3/2014) and by the project SIX CZ 1.05/2.1.00/03.0072.

\section{References}

Campioli E, Rustichelli C, Avallone R 2012: N-3 dietary supplementation and lipid metabolism: differences between vegetable- and fish-derived oils. J Funct Foods 4: 207-212

Chen J, Jiang Y, Ma KY, Chen F, Chen ZY 2011: Microalga decreases plasma cholesterol by down-regulation of intestinal NPC1L1, hepatic LDL receptor, and HMG-CoA reductase. J Agr Food Chem 59: 6790-6797

Czech National Council Act No 246/1992 Coll. on the protection of animals against cruelty, as amended by Act No 162/1993 Coll., Act No 193/1994 Coll., Act No 243/1997 Coll., finding of the Constitutional Court No 30/1998 Coll., Act No 77/2004 Coll., Act No 413/2005 Coll., Act No 77/2006 Coll. and Act No 312/2008 Coll. Prague, 2008

Eslick GD, Howe PRC, Smith C, Priest R, Bensoussan A 2009: Benefits of fish oil supplementation in hyperlipidemia: a systematic review and meta-analysis. Int J Cardiol 136: 4-16

Fattore E, Bosetti C, Brighenti F, Agostoni C, Fattore G 2014: Palm oil and blood lipid-related markers of cardiovascular disease: a systematic review and meta-analysis of dietary intervention trials. Am J Clin Nutr 99: $1331-1350$

Ferramosca A, Conte L, Zara V 2012: A krill oil supplemented diet reduces the activities of the mitochondrial tricarboxylate carrier and of the cytosolic lipogenic enzymes in rats. J Anim Physiol Anim Nutr 96: 295-306

Jacobson TA, Glickstein SB, Rowe JD, Soni PN 2012: Effects of eicosapentaenoic acid and docosahexaenoic acid on low-density lipoprotein cholesterol and other lipids: A review. J Clin Lipidol 6: 5-18

Komprda T 2012: Eicosapentaenoic and docosahexaenoic acids as inflammation-modulating and lipid homeostasis influencing nutraceuticals: A review. J Funct Foods 4: 25-38 
Komprda T, Zorníková G, Knoll A, Vykoukalová Z, Rozíková V, Škultéty O, Krobot R 2014: Effect of dietary eicosapentaenoic and docosahexaenoic acid on expression of rat liver genes controlling cholesterol homeostasis and on plasma cholesterol level. Czech J Anim Sci 59: 391-398

Komprda T, Zorníková G, Rozíková V, Borkovcová M, Przywarová A 2013: The effect of dietary Salvia hispanica seed on the content of n-3 long-chain polyunsaturated fatty acids in tissues of selected animal species, including edible insects. J Food Comp Anal 32: 36-43

König B, Koch A, Spielmann J, Hilgenfeld C, Stangl GI, Eder K 2007: Activation of PPAR $\alpha$ lowers synthesis and concentration of cholesterol by reduction of nuclear SREBP-2. Biochem Pharmacol 73: 574-585

Lu J, Borthwick F, Hassanali Z, Wang Y, Mangat R, Ruth M, Shi D, Jaeschke A, Russel JC, Field CJ, Proctor SD, Vine DF 2011: Chronic dietary n-3 PUFA intervention improves dislipidaemia and subsequent cardiovascular complications in the JSR:LA-cp rat model of the metabolic syndrome. Brit J Nutr 105: 1572-1582

Mozaffarian D, Wu JH 2011: Omega-3 fatty acids and cardiovascular disease: effects on risk factors, molecular pathways, and clinical events. J Am Coll Cardiol 58: 2047-2067

Ooi EMM, Ng TWK, Watts GF, Barrett PHR 2013: Dietary fatty acids and lipoprotein metabolism: new insights and updates. Curr Opin Lipidol 24: 192-197

Popović T, Borozan S, Arsić A, Debeljak-Martačić J, Vučić V, de Luka S, Milovanović I, Trbović A, Glibetić M 2011: Effects of n-3 supplementation on plasma and liver phospholipid fatty acids profile in aged Wistar rats. Croat Chem Acta 84: 73-79

Poudyal H, Kumar SA, Iyer A, Waanders J, Ward LC, Brown L 2013: Responses to oleic, linoleic and $\alpha$-linolenic acids in high-carbohydrate, high-fat diet-induced metabolic syndrome in rats. J Nutr Biochem 24: 1381-1392

Takahashi Y 2011: Soy protein and fish oil independently decrease serum lipid concentrations but interactively reduce hepatic enzymatic activity and gene expression involved in fatty acid synthesis in rats. J Nutr Sci Vitaminol 57: 56-64 